\title{
Influence of High Dose Inhaled Steroids on Hypothalamo-Pituitary-Adrenal Axis Function in Japanese Patients with Asthma: A Comparison over the Course of Time
}

\author{
Tsuyoshi Hasegawa, Kyosuke Ishinara, Hiroshi FujII, Takashi Hajiro, Isao Watanabe, \\ Takashi Nishimura, Miki OKaZaKi, Nobuyuki KataKami and Bun-ichi Umeda
}

\begin{abstract}
Although the influence of high dose inhaled steroids on hypothalamo-pituitary-adrenal (HPA) function in patients with asthma has been extensively studied worldwide, there has been limited information on Japanese asthmatics, especially in terms of a prospective analysis of HPA function in the course of time. We analyzed the changes in HPA function using 2 serial short tetracosactrin tests (STT) separated by an interval of one year in 11 Japanese asthmatics who were treated with high dose inhaled steroids alone [beclomethasone dipropionate (BDP); mean dose $982 \mu \mathrm{g} / \mathrm{day}$ ] during the period between 2 STTs. Mean values of plasma cortisol before administration of ACTH, maximum cortisol and the rise in cortisol in response to ACTH in the $2 \mathrm{STT}$ sere 7.8, 20.5 and 12.7 $\mu \mathrm{g} / \mathrm{dl}$ for the 1 st test, and 8.9, 23.6 and $14.7 \mu \mathrm{g} / \mathrm{dl}$ for the $2 \mathrm{nd}$ test, respectively. Overall, there was no significant change in the course of time in each of these 3 values. Although the results of the 1st STT proved to be abnormal in 3 patients who had been receiving systemic steroids before their 1st STT, they improved uniformly in their 2nd STT. In the remaining 8 patients, who had never received systemic steroids, 4 patients showed improvements while the other 4 showed deterioration in HPA function in their serial STTs over the course of time. The dose of BDP was $800 \mu \mathrm{g} / \mathrm{day}$ in the former 4 patients, while it was $1,200 \mu \mathrm{g} /$ day in the latter 4 . Furthermore, only one patient, in whom BDP had been increased from $800 \mu \mathrm{g} /$ day to $1,200 \mu \mathrm{g} /$ day between the 2 tests, developed an abnormal response in the 2nd STT. On the other hand, one patient whose BDP dose was increased from $800 \mu \mathrm{g} /$ day to $1,600 \mu \mathrm{g} /$ day showed an improvement in HPA function in the 2nd test. These results indicate that the threshold dose of BDP which may cause HPA suppression in Japanese asthmatics lies between $800-1,200 \mu \mathrm{g} /$ day, although there is a large inter-individual variation in terms of such doses.
\end{abstract}

(Internal Medicine 35: 362-366, 1996)

Key words: beclomethasone dipropionate (BDP), side effects, adrenal suppression

\section{Introduction}

Inhaled steroids are the most effective therapy for asthma currently available, and have now become first-line therapy for chronic asthma internationally (1). Although it is clear that their advantage in asthma treatment lies in their excellent topical anti-inflammatory effect with minimal systemic effects, several unwanted systemic side effects may occur, especially when high doses of inhaled steroids are used (2). Among these, suppression of the hypothalamo-pituitary-adrenal (HPA) axis is important not only as a serious systemic side effect itself but also as a marker of other systemic effects (3).

Although the influence of high dose inhaled steroids on HPA function has been extensively studied, especially in Europe (49), there has been limited information on such an influence in Japanese asthmatics. As a racial difference in sensitivity to exogenous steroids may exist (10), the results of the reported European studies may not be applicable to Japanese patients.

From the Department of Pulmonary Medicine, Kobe City General Hospital, Kobe

Received for publication September 13, 1995; Accepted for publication February 26, 1996

Reprint requests should be addressed to Dr. Tsuyoshi Hasegawa, the Department of Pulmonary Medicine, Kobe City General Hospital, 4-6 Minatojimanakamachi, Chuo-ku, Kobe 650 
Furthermore, some studies included asthmatics who had been taking concomitant systemic steroids. Under such circumstances, it may be difficult to discuss the influence of inhaled steroids separately from that of systemic steroids.

We previously conducted a cross-sectional study of HPA axis function in Japanese asthmatics which revealed no suppression in patients inhaling less than $800 \mu \mathrm{g} / \mathrm{day}$ of beclomethasone dipropionate (BDP) (11). In the present study, a change in HPA function in the course of time was examined using serial short tetracosactrin tests in Japanese asthmatics treated with high dose inhaled steroids $(800 \mu \mathrm{g} /$ day or more of BDP) alone.

\section{Materials and Method}

In our previous study, 94 patients were given a short tetracosactrin test (STT). Of these, 11 were selected to undergo a 2nd test. These patients, who therefore formed the basis of our analysis in the present study, (a) inhaled $800 \mu \mathrm{g} /$ day or more of $\mathrm{BDP}$ and (b) received no systemic steroids (neither short courses nor regular use) during the period between their 2 STTs.

Patients were requested to come to the outpatient clinic of Kobe City General Hospital between 9:30 and 11:00 AM. Following venous sampling for measurement of serum cortisol (basal cortisol), a STT was performed using a $0.25 \mathrm{mg}$ i.v. dose of tetracosactid (cortrocin). Venous sampling was repeated after 30 and 60 minutes, and the higher cortisol level of the 2 samplings was defined as the maximum cortisol. HPA suppression was indicated when maximum cortisol failed to reach 18 $\mu \mathrm{g} / \mathrm{dl}$. The 2nd STT was intended to be performed approximately one year after the 1st STT although in the end, the interval between the 2 tests was actually $392 \pm 28$ days (mean \pm SD).
Statistical analysis was performed using STATVIEW 4.0. Changes in serum cortisol in the course of time were compared using Wilcoxon signed-rank test. Comparisons of several cortisol values between patients with and without previous systemic steroids were made using unpaired $t$ test.

\section{Results}

Selected characteristics of the study subjects are shown in Table 1 . The mean age was 53 years old. There were 4 males and 7 females. Doses of BDP were between 800 and 1,600 $\mu \mathrm{g} /$ day, and the mean duration of BDP inhalation was 1,468 days. Although no patients received any systemic steroids between their 2 STTs, 3 patients (cases 9, 10 and 11 in Table 1) had received short courses of oral steroids before their 1 st test. These 3 patients had also received regular systemic steroids until about 66,36 and 59 months, respectively, before their 1st STTs. In these patients, their 1st STTs were performed at least 4 weeks after the completion of the final course of their short courses of oral steroids. The remaining 8 patients had never received regular, nor short courses of oral steroids.

Serum cortisol before the administration of basal cortisol, maximum cortisol, and the rise in cortisol in response to $\mathrm{ACTH}$ in the 2 serial STTs are shown in Table 2. Mean \pm SD of basal cortisol, maximum cortisol and the rise in cortisol was $7.8 \pm 2.6$ $\mu \mathrm{g} / \mathrm{dl}, 20.5 \pm 6.4 \mu \mathrm{g} / \mathrm{dl}$ and $12,7 \pm 5.9 \mu \mathrm{g} / \mathrm{dl}$, respectively for the 1 st test, and $8.9 \pm 2.5 \mu \mathrm{g} / \mathrm{dl}, 23.6 \pm 4.8 \mu \mathrm{g} / \mathrm{dl}$ and $14.7 \pm 5.6 \mu \mathrm{g} / \mathrm{dl}$, respectively for the 2 nd test. They were all within their normal ranges, and none of the changes in the 2 tests was statistically significant. Mean levels of maximum cortisol in the 1st STT were significantly lower in patients with previous systemic steroids than in patients without them $(14.4 \pm 4.4 \mathrm{vs} 22.8 \pm 5.5 \mu \mathrm{g} /$ $\mathrm{dl}, \mathrm{p}<0.05)$. They became identical in the 2 nd STT $(23.6 \pm 6.3 \mathrm{vs}$

Table 1. Patient Profile

\begin{tabular}{|c|c|c|c|c|c|c|}
\hline \multirow[b]{2}{*}{ Case } & \multirow[b]{2}{*}{ Sex } & \multirow[b]{2}{*}{ Age } & \multirow{2}{*}{$\begin{array}{l}\text { Previous } \\
\text { systemic } \\
\text { steroids }\end{array}$} & \multirow{2}{*}{$\begin{array}{c}\text { Duration of } \\
\text { BDP use } \\
\text { (days) }\end{array}$} & \multicolumn{2}{|c|}{ Doses of BDP ( $\mu \mathrm{g} /$ day $)$} \\
\hline & & & & & $\begin{array}{l}\text { At the time of } \\
\text { the } 1 \text { st test }\end{array}$ & $\begin{array}{c}\text { At the time of } \\
\text { the } 2 \text { nd test }\end{array}$ \\
\hline 1 & $\mathrm{~F}$ & 52 & - & 1,092 & 800 & 800 \\
\hline 2 & M & 71 & - & 1,295 & 800 & 1,600 \\
\hline 3 & $\mathrm{~F}$ & 53 & - & 667 & 1,200 & 1,200 \\
\hline 4 & $\mathrm{~F}$ & 73 & - & 554 & 1,200 & 1,200 \\
\hline 5 & $\mathrm{~F}$ & 31 & - & 2,515 & 500 & 800 \\
\hline 6 & $\mathrm{~F}$ & 62 & - & 1,490 & 800 & 800 \\
\hline 7 & $\mathrm{~F}$ & 39 & - & 1,607 & 800 & 1,200 \\
\hline 8 & M & 61 & - & 1,981 & 800 & 800 \\
\hline 9 & $\mathrm{M}$ & 53 & + & 930 & 800 & 800 \\
\hline 10 & M & 42 & + & 1,813 & 800 & 800 \\
\hline 11 & M & 44 & + & 2,199 & 1,000 & 800 \\
\hline Mean \pm SD & & $53 \pm 13$ & & $1,468 \pm 630$ & $864 \pm 201$ & $982 \pm 275$ \\
\hline
\end{tabular}

BDP: beclomethasone dipropionate. 
Hasegawa et al

Table 2. Results of Two Serial Short Tetracosactrin Tests

\begin{tabular}{|c|c|c|c|c|c|c|c|c|}
\hline \multirow[t]{2}{*}{ Case } & \multicolumn{2}{|c|}{$\begin{array}{l}\text { Basal cortisol } \\
\qquad(\mu \mathrm{g} / \mathrm{dl})\end{array}$} & \multicolumn{2}{|c|}{$\begin{array}{l}\text { Maximum cortisol } \\
\qquad(\mu \mathrm{g} / \mathrm{dl})\end{array}$} & \multicolumn{2}{|c|}{$\begin{array}{l}\text { Rise in cortisol } \\
(\mu \mathrm{g} / \mathrm{dl})\end{array}$} & \multicolumn{2}{|c|}{ HPA suppression* } \\
\hline & 1 st test & 2nd test & 1 st test & 2 nd test & 1st test & 2nd test & 1 st test & 2nd test \\
\hline 1 & 7.0 & 8.0 & 28.6 & 27.4 & 21.6 & 16.7 & - & - \\
\hline 2 & 5.6 & 7.3 & 14.4 & 20.5 & 8.8 & 13.2 & - & - \\
\hline 3 & 10.1 & 5.2 & 21.4 & 19.3 & 11.3 & 14.1 & - & - \\
\hline 4 & 14.1 & 8.3 & 30.6 & 29.4 & 16.5 & 21.1 & - & - \\
\hline 5 & 7.9 & 7.4 & 19.8 & 21.9 & 11.9 & 14.5 & - & - \\
\hline 6 & 8.4 & 9.6 & 27.3 & 30.2 & 18.9 & 20.6 & - & - \\
\hline 7 & 5.5 & 11.7 & 21.4 & 17.5 & 15.9 & 5.8 & - & + \\
\hline 8 & 7.6 & 13.9 & 19.1 & 25.7 & 11.5 & 11.8 & - & - \\
\hline 9 & 6.5 & 11.1 & 9.3 & 17.4 & 2.8 & 6.3 & + & + \\
\hline 10 & 8.6 & 8.8 & 16.8 & 23.4 & 8.2 & 14.6 & + & - \\
\hline 11 & 4.6 & 6.5 & 17.1 & 30.0 & 12.5 & 23.5 & - & - \\
\hline \multicolumn{9}{|c|}{ Mean \pm} \\
\hline $\mathrm{SD}$ & $7.8 \pm 2.6$ & $8.9 \pm 2.5$ & $20.5 \pm 6.4$ & $23.6 \pm 4.8$ & $12.7 \pm 5.9$ & $14.7 \pm 5.6$ & & \\
\hline
\end{tabular}

* Maximum cortisol $\leqq 18 \mu \mathrm{g} / \mathrm{dl}$ and rise in cortisol $\leqq 7 \mu \mathrm{g} / \mathrm{dl}$.

$23.7 \pm 4.6 \mu \mathrm{g} / \mathrm{dl}$ ), as a consequence of dramatic improvement in HPA function in the course of time in patients with previous systemic steroids. The mean difference in maximum cortisol between the 1st and the 2nd STT was significantly higher in patients with previous systemic steroids than in patients without them $(9.2 \pm 3.3$ vs $0.8 \pm 4.2 \mu \mathrm{g} / \mathrm{dl}, \mathrm{p}<0.05)$.

When we analyzed the 8 systemic steroids naive subjects only, cortisol levels in 2 serial tests were almost identical $(8.3 \pm 2.8 \mu \mathrm{g} / \mathrm{dl}$ vs $8.9 \pm 2.8 \mu \mathrm{g} / \mathrm{dl}$ for basal cortisol, $22.8 \pm 5.5 \mu \mathrm{g} /$ dl vs $23.7 \pm 4.6 \mu \mathrm{g} / \mathrm{dl}$ for maximum cortisol and $14.6 \pm 4.4 \mu \mathrm{g} / \mathrm{dl}$ vs $15 \pm 4.9 \mu \mathrm{g} / \mathrm{dl}$ for the rise in cortisol, respectively). In these patients, there was no uniform tendency regarding changes in HPA function in the 2 tests. Four of them revealed improvement in their maximum cortisol, while the other 4 experienced deterioration in the course of time. The doses of BDP were 800 $\mu \mathrm{g} /$ day in 3 of the 4 patients who revealed improvement, and $1,200 \mu \mathrm{g} /$ day for 3 of the 4 patients who showed deterioration. One female patient (case 7) newly developed an abnormal response to ACTH in her 2 nd test. She had been inhaling 800 $\mu \mathrm{g} /$ day of BDP at the time of her 1st test, and the dose was increased to $1,200 \mu \mathrm{g} /$ day between the two tests.

\section{Discussion}

\section{Which test should be used to examine HPA function?}

HPA function has been used as a marker of other systemic side effects because it is most readily measurable. However, there is no consensus about which test should be used to examine HPA function itself. Holt et al (12) reported that short tetracosactrin tests are not as sensitive as 24-h urinary cortisol, while Brown et al (13) reported they are equally sensitive and, indeed, they are more sensitive than a single measurement of 9:00 AM plasma cortisol. Short tetracosactrin tests were used in the present study due to both the ease of use in an outpatient setting and their sensitivity.

Furthermore, there seems to be no consensus on diagnosing HPA dysfunctions in STT. Some use maximum cortisol (8) or the rise in cortisol (12) alone, others $(4,6,7)$ use the combination of these. In the present study, all STTs were performed between 9:30 AM and 11:00 AM, but not at exactly the same time. We realize that basal cortisol value may be affected by the circadian rhythm of plasma cortisol, and the rise in cortisol may also be affected because it was calculated using basal cortisol. Because of this, we diagnosed HPA dysfunction only by the maximum cortisol level in the present study. As a cut-off value to diagnose an abnormal response, many previous studies used either $500 \mathrm{nM}$ (approximately $17.3 \mu \mathrm{g} / \mathrm{dl}$ ) or $18 \mu \mathrm{g} / \mathrm{dl}$; we employed the latter cut-off value.

\section{Influence of systemic steroids}

Asthmatics who need high dose inhaled steroids to control their symptoms generally have severe asthma. Naturally, many of them sometimes need either short courses or regular use of systemic steroids. A review of the literature revealed that some of the reports which deal with inhaled steroids and HPA function analyzed asthmatics both with and without systemic steroids concomitantly. In this situation, it may be difficult to discuss the influence of inhaled steroids separately from that of systemic steroids.

In the present study, we selected 11 asthmatics who had never used any systemic steroids between their 2 STTs, but 3 of them had received such drugs before their 1st STT. In other words, these patients had recently succeeded in withdrawing from systemic steroids with the use of inhaled steroids. Although the results of the 1 st STTs in all 3 patients revealed HPA suppression, they experienced dramatic improvements in HPA 
function in the course of time in their 2nd STTs. The results of the 1st STTs in these 3 patients might have been influenced largely by their previous systemic steroids, because the influence of systemic steroids seems to persist several years after their completion (14).

\section{Safety of high dose inhaled steroids in Japanese asthmatics}

Of 8 patients who had never taken systemic steroids, 4 had a reduced maximum cortisol level, while the other 4 had an improved maximum cortisol level in their 2nd STTs. The doses of BDP were $800 \mu \mathrm{g} /$ day in 3 of the 4 patients who experienced improvement, and 1,200 $\mu \mathrm{g}$ /day for 3 of the 4 patients who showed deterioration. Furthermore, in one patient who newly developed an abnormal response to ACTH in her 2nd test, BDP was increased from $800 \mu \mathrm{g} / \mathrm{day}$ to $1,200 \mu \mathrm{g} /$ day between the two tests. These results suggest that a threshold dose resulting in HPA suppression in Japanese asthmatics exists between 800 and $1,200 \mu \mathrm{g} /$ day. In other words, an international consensus (2) which suggests that doses up to $1,000 \mu \mathrm{g} /$ day are safe in terms of systemic side effects, could also be applied to Japanese asthmatics.

However, one patient whose BDP dose was increased from $800 \mu \mathrm{g} /$ day to $1,600 \mu \mathrm{g} /$ day, showed an improvement of HPA function in his 2 nd test. This suggests that an increased dose of BDP may not consistently be associated with HPA dysfunction in certain subjects. A review of the literature also revealed that the relationship between doses and HPA function is not always clear.

Smith and Hodson (4) reported that maximum cortisol in STTs was similar in asthmatics inhaling both 1,000 and 1,500 $\mu \mathrm{g} /$ day, but significantly lower in asthmatics inhaling $2,000 \mu \mathrm{g} /$ day of BDP. Boe et al (5) prospectively compared efficacy and HPA suppression with $1.6 \mathrm{mg}$ of BDP and $2.0 \mathrm{mg}$ of fluticasone propionate, and reported that HPA suppression developed only when $2.0 \mathrm{mg}$ of fluticasone was used. On the other hand, Brown et al (6) examined 78 asthmatics who were inhaling 1,200$2,650 \mu \mathrm{g} / \mathrm{day}$ of BDP or budesonide, and reported that there was no significant correlation between doses of BDP and HPA axis function. Altman et al (7) performed STTs in 143 asthmatics who were inhaling $800,1,200,1,600 \mu \mathrm{g} / \mathrm{day}$ of triamcinolone acetonide. They repeated STTs before and 2 weeks, 1 month, 3 months and 6 months after treatment. There was no difference in the incidence of HPA suppression either according to dose or time. Three patients were diagnosed as having HPA suppression. Two of them were inhaling $1,600 \mu \mathrm{g} / \mathrm{day}$, but the other was inhaling $800 \mu \mathrm{g} / \mathrm{day}$. Furthermore, this latter patient developed HPA suppression only 2 weeks after starting treatment with inhaled steroids. It was not clear why the patient with the lowest dose developed HPA suppression so early, while the majority of patients with the highest dose revealed no suppression throughout the 6 months of the study period, although interindividual differences in sensitivity to exogenous steroids might play an import role. Results of a prospective dose escalation study of inhaled steroids also suggest that there is wide interindividual variation in doses of BDP resulting in HPA suppression (8).
In consideration of this wide inter-individual variation, there may likewise be racial differences in sensitivity to exogenous steroids. Recently, Tornatore et al (10) reported that there was a difference in methylprednisolone clearance between black and white renal transplant recipients. In this context, we reanalyzed some of the previous reports. In a dose range of inhaled steroids between 800 and $1,200 \mu \mathrm{g} /$ day without the use of concurrent systemic steroids, Smith and Hodson (4) reported 1 out of 34 and Altman et al (7) reported 1 out of 78 patients with HPA suppression. Because these studies used different drugs and there was also a difference in the criteria for HPA suppression, they are not directly comparable with the results of the present study. But if we compare our results with the combined total of these 2 previous reports, the incidence of HPA suppression with a dose of inhaled steroids between $800-1,200 \mu \mathrm{g} / \mathrm{day}$ was 1 out of $7(14.3 \%)$ against 2 out of $112(1.8 \%)$. Although the results of this comparison are not conclusive due to the very small sample size of the present study, they suggest that Japanese asthmatics could be more sensitive to this dose range of inhaled steroids than the European population.

All drugs should be evaluated in terms of the balance between their efficacy and their safety (15). The fact that inhaled steroids have been extensively used during the past 20 years and are still recognized as the first line treatment for persistent asthma, suggests that these drugs do not have serious side effects which outweigh their clinical efficacy. But one should recognize the wide inter-individual variation in sensitivity to exogenous steroids. If the same dose of inhaled steroids is used in different patients, there may be a difference both in their efficacy and their safety, and as a consequence, in the balance between the two. Thus, when doses of $800 \mu \mathrm{g} / \mathrm{day}$ or more of BDP are used, screening for HPA function should routinely be performed. And when a decision needs to be made as to whether the doses of BDP should be increased or other drugs should be added, careful attention should be paid, case by case, for the balance between efficacy and safety of these different strategies.

From the results of our study, we have drawn the following conclusions: 1) The international consensus on the safety of prolonged treatment with high dose inhaled steroids is generally applicable to Japanese asthmatics, and 2) In the introduction to a treatment with high dose inhaled steroids, careful attention shuld be paid to the wide inter-individual variation in sensitivity to exogenous steroids.

Acknowledgements: The author would like to thank Mr. Geoff Rupp (Language Resources Ltd.) for his assistance in the proofreading and editing of this manuscript.

\section{References}

1) Global strategy for asthma management and prevention. NHLBI/WHO workshop report. National Institutes of Health, National Heart, Lung, and Blood Institute. NIH Publication No. 95-3659, 1995.

2) Geddes DM. Inhaled corticosteroids: benefits and risks. Thorax 47: 404, 1992 (editorial) (see comments).

3) Barnes NC. Safety of high-dose inhaled corticosteroids. Respir Med 87 Suppl A: 27, 1993. 


\section{Hasegawa et al}

4) Smith MJ, Hodson ME. Effects of long term inhaled high dose beclomethasone dipropionate on adrenal function. Thorax 38: 676, 1983.

5) Boe J, Bakke P, Rodolen T, Skovlund E, Gulsvik A. High-dose inhaled steroids in asthmatics: moderate efficacy gain and suppression of the hypothalamic-pituitary-adrenal (HPA) axis. Research Council of the Norwegian Thoracic Society. Eur Respir J 7: 2179, 1994.

6) Brown PH, Blundell G, Greening AP, Crompton GK. Hypothalamopituitary-adrenal axis suppression in asthmatics inhaling high dose corticosteroids. Respir Med 85: 501, 1991.

7) Altman LC, Findlay SR, Lopez M, et al. Adrenal function in adult asthmatics during long-term daily treatment with $800,1,200$, and 1,600 $\mu \mathrm{g}$ triamcinolone acetonide. Multicenter study. Chest 101: 1250, 1992.

8) Brown PH, Greening AP, Crompton GK. Large volume spacer device and the influence of high dose beclomethasone dipropionate on hypothalamopituitary-adrenal axis function. Thorax 48: 233, 1993.

9) Fabbri L, Burge PS, Croonenborgh L, et al, and International Study Group. Comparison of fluticasone propionate with beclomethasone dipropionate in moderate to severe asthma treated for one year. Thorax 48: 817, 1993 (see comments).
10) Tornatore KM, Biocevich DM, Reed K, Tousley K, Singh JP, Venuto RC. Methylprednisolone pharmacokinetics, cortisol response, and adverse effects in black and white renal transplant recipients. Transplantation 59: $729,1995$.

11) Hasegawa $T$, Ishihara $K$, Matsumoto $H$, et al. Treatment modalities and hypothalamo-pituitary-adrenal axis suppression in Japanese patients with asthma. Nippon Kyobu Shikkan Gakkai Zasshi 32: 757, 1994.

12) Holt PR, Lowndes DW, Smithies E, Dixon GT. The effect of an inhaled steroid on the hypothalamic-pituitary-adrenal axis - which tests should be used? Clin Exp Allergy 20: 145, 1990.

13) Brown PH, Blundell G, Greening AP, Crompton GK. Screening for hypothalamo-pituitary-adrenal axis suppression in asthmatics taking high dose inhaled corticosteroids. Respir Med 85: 511, 1991.

14) Harrison BDW, Rees LH, Cayton RM, Nabarro JDN. Recovery of hypothalamo-pituitary-adrenal function in asthmatics whose oral steroids have been stopped or reduced. Clin Endocrinol (Oxf) 17: 109, 1982.

15) Barnes PJ. Inhaled glucocorticoids for asthma. New Engl J Med 332: 868, 1995. 